\title{
Concerning the Beckmann Rearrangement of Aryl Heteryl Ketoxime Ions
}

\author{
Hans-Fr. Grützmacher† and Christian Römer
}

Fakultät für Chemie, Universität Bielefeld, Universitätsstr. 25, 4800 Bielefeld 1, West Germany

\begin{abstract}
The possible Beckmann rearrangement of aryl heteryl ketoxime ions has been investigated by studies on the $70 \mathrm{eV}$ mass spectra, metastable ion spectra and collision induced dissociation spectra of pairs of isomeric ketoximes and corresponding amides. Aryl cycloalkyl ketoximes were also studied, and the molecular ions of these and the corresponding amides showed no evidence of interconversion. The introduction of the heterocyclic moieties made little change to this situation although some novel rearrangements were observed.
\end{abstract}

\section{INTRODUCTION}

The Beckmann rearrangement of ketoximes under acidic conditions is a well known reaction in organic chemistry. Recently, Maquestiau et al. ${ }^{1}$ showed that a Beckmann type of rearrangement accompanies the loss of $\mathrm{H}_{2} \mathrm{O}$ from protonated ketoxime ions under methane and isobutane chemical ionization conditions in a mass spectrometer by proving a nitrilium cationstructure for the resulting fragment ions. This is in accord with the accepted mechanism of the Beckmann rearrangement. Interestingly, however, a Beckmann rearrangement has also been reported by Kallury et al. for the odd-electron molecular ions of certain aryl heteryl ketoximes generated by electron impact. ${ }^{2}$ We investigated the fragmentations of some aryl ketoximes and the isomeric amides by mass analysed ion kinetic energy (MIKE) and collisional activation (CA) MIKE spectrometry. If interconversion occurs between the molecular ions of the ketoximes and the corresponding amides, common features are expected to appear in the MIKE and CA MIKE spectra of the isomeric molecular ions. The compounds investigated are cyclopentyl phenyl ketoxime (1) and the isomeric $N$-cyclopentylbenzamide (2), cyclohexyl phenyl ketoxime (3) and $N$-cyclohexylbenzamide (4), $\alpha$-(1-pyrrolidinyl)benzaldoxime (5) and the isomeric 1-benzamidopyrrolidine (6) and 2-(1-piperidyl)benzaldoxime (7) and 1-benzamidopiperidine $(\mathbf{8})$. The aryl heteryl ketoximes 5 and 7 have been investigated by Kallury

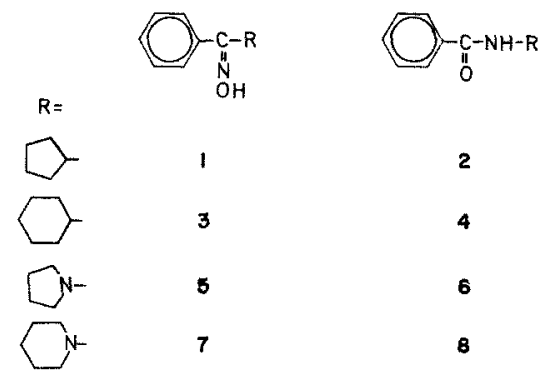

† Author to whom correspondence should be addressed. et $a l^{2}$ and particularly for 5 a Beckmann rearrangement of the molecular ions to 6 has been proposed, while 7 rearranges to a much lesser extent. The 'normal' aryl cycloalkyl ketoximes $\mathbf{1}$ and $\mathbf{3}$ are included for a comparison.

\section{EXPERIMENTAL}

The $70 \mathrm{eV}$ mass spectra were recorded on a MAT 311A mass spectrometer, ion source temperature $150^{\circ} \mathrm{C}$, with direct sample insertion. The MIKE and CA MIKE spectra were recorded on a VG ZAB $2 F$ mass spectrometer at $70 \mathrm{eV}$, ion source temperature $\sim 180^{\circ} \mathrm{C}$, with direct insertion. The field free region collision gas was He.

\section{RESULTS AND DISCUSSION}

The $70 \mathrm{eV}$ mass spectra of 1-8 are presented in Table 1 , and the MIKE and CA MIKE spectra of the

Table 1. Characteristic ions in the $70 \mathrm{eV}$ mass spectra of 1-8

\begin{tabular}{rccccccccc}
\hline$[\mathrm{M}]^{+}$ & 50.8 & 34.5 & 71.6 & 32.6 & 15.7 & 3.3 & 13.2 & 3.0 \\
{$[\mathrm{M}-\mathrm{H}]^{+}$} & 40.9 & 3.7 & 29.2 & 1.9 & - & - & - & - \\
{$[\mathrm{M}-\mathrm{OH}]^{+}$} & 65.8 & - & 100 & - & 0.8 & - & 2.2 & 0.2 \\
$m / z$ & 148 & 100 & - & 74.2 & - & - & - & - & - \\
$m / z$ & 130 & 12.0 & - & 10.0 & - & 1.0 & - & 1.4 & - \\
$m / z$ & 129 & 13.6 & - & 13.0 & - & 1.6 & - & 0.7 & - \\
$m / z$ & 122 & 0.8 & 67.6 & 2.7 & 79.0 & - & 2.0 & - & 27.3 \\
$m / z$ & 115 & 15.9 & - & 11.1 & - & - & - & - & - \\
$m / z$ & 105 & 3.3 & 100 & 4.5 & 100 & 0.5 & 28.8 & 0.3 & 31.0 \\
$m / z$ & 104 & 72.2 & 1.4 & 74.7 & 1.5 & 20.2 & 1.0 & 19.7 & 0.9 \\
$m / z$ & 103 & 17.7 & - & 15.5 & - & 7.3 & 1.0 & 5.1 & 2.9 \\
$m / z$ & 99 & - & - & - & - & - & - & - & 100 \\
$m / z$ & 91 & 21.3 & - & 28.3 & - & 1.1 & - & 1.3 & - \\
$m / z$ & 85 & - & - & - & - & - & 88.4 & 3.7 & - \\
$m / z$ & 84 & - & - & - & - & - & 1.0 & 100 & 28.2 \\
$m / z$ & 83 & - & - & - & - & - & - & - & 80.6 \\
$m / z$ & 70 & 0.5 & - & 0.5 & - & 100 & 100 & 0.5 & 3.3 \\
\hline
\end{tabular}

${ }^{a}$ Corrected for ${ }^{13} \mathrm{C}$.

CCC-0030-493X/82/0017-0318\$01.50 
Table 2. MIKE spectra of the molecular ions of 1-8

\begin{tabular}{|c|c|c|c|c|c|c|c|c|}
\hline & 1 & 2 & 3 & 4 & 5 & 6 & 7 & 8 \\
\hline$[\mathrm{M}-\mathrm{H}]^{+}$ & 42 & 85 & 26 & 53 & - & 24 & - & 13 \\
\hline$\left[\mathrm{M}-\mathrm{CH}_{3}\right]^{+}$ & 3 & 1 & 5 & 2 & 5 & 2 & 6 & 2 \\
\hline$[\mathrm{M}-\mathrm{OH}]^{+}$ & 55 & - & 68 & - & 47 & 10 & 88 & 31 \\
\hline$\left[\mathrm{M}-\mathrm{CH}_{2} \mathrm{NO}\right]^{+}$ & - & - & - & - & - & 36 & - & 17 \\
\hline $\mathrm{m} / \mathrm{z} 122$ & - & 14 & - & 44 & - & 3 & - & 5 \\
\hline $\mathrm{m} / \mathrm{z} 100$ & & & & & - & - & 1 & 18 \\
\hline $\mathrm{m} / \mathrm{z} \quad 86$ & & & & & 2 & 1 & - & - \\
\hline $\mathrm{m} / \mathrm{z} \quad 84$ & & & & & - & - & 5 & 3 \\
\hline $\mathrm{m} / \mathrm{z} \quad 70$ & & & & & 43 & 23 & - & - \\
\hline
\end{tabular}

molecular ions are presented in Tables 2 and 3 respectively. The molecular ions of 1-4 fragment as expected without any indication of an interconversion between ketoxime ions and amide ions. The loss of $\mathrm{H}$ and $\mathrm{HO}^{\circ}$, respectively, and the formation of $\mathrm{C}_{6} \mathrm{H}_{6} \mathrm{C} \equiv \mathrm{N}^{+} \mathrm{H}$ ions $\mathrm{m} / z 104$ and ions $\mathrm{m} / z 148$ from phenyl ketoxime ions is known. ${ }^{3}$ The two former reactions are also observed for the fragmentation of metastable molecular ions. In contrast, the isomeric benzamide ions fragment mainly by the reaction sequence $[\mathrm{M}]^{+\cdot} \rightarrow m / z$ $122 \rightarrow m / z \quad 105 \rightarrow m / z \quad 77$. The formation of protonated benzamide ions $m / z 122$ is also observed from metastable $[2]^{+\cdot}$ and $[4]^{+\cdot}$ ions, in addition to loss of a H-atom (Table 2), and corresponds obviously to an energetically favoured fragmentation path of these substituted benzamide ions. Since ions $\mathrm{m} / z 122$ are observed neither in the $70 \mathrm{eV}$ mass spectra nor in the MIKE spectra and CA MIKE spectra of the ketoximes, interconversion of the ions $[1]^{+\cdot} \rightleftarrows[2]^{+\cdot}$ and $[3]^{++} \rightleftarrows[4]^{+\cdot}$, respectively, in a mass spectrometer can be excluded.

The $70 \mathrm{eV}$ mass spectrum of 5 (Fig. 1) obtained with both our instruments is very different from that re-

\section{Table 3. CA MIKE spectra of the molecular ions of 1-8*}

1: $188(436), 174(118), 172(415, \sim 157(12), \sim 153$ (16), $148(14), \sim 137(9), \sim 125(8), \sim 115(7), 104(9), 92(6)$, $-84(5),-70(5), \sim 61(4)$

2: $188(133), 164(2), 160(2), 148(2), 131(37), 122(39)$, $116(35), 113(2), 105(2), 98(2), 92(7), 85(3), \sim 71(2)$.

3: 202 (148), $188(79), 186$ (222), $175(5), \sim 171(12), \sim 162$ (5), $\sim 155(9), \sim 151(6), 148(7), \sim 144(6), \sim 139(6), \sim 127(5)$, $121(3), 117(7), \sim 106(8), 98(3), \sim 94(4)$.

4: $202(62), 188(2), 166(3), 160(2), 133(30), 122(38), 118(40)$, $105(2), 98(4), 94(8), 86(3), 75(3), 72(3), 63(2)$.

5: $189(12), 175(2), 173(10), 162(3), 129(2), 116(16), 104(2)$, $92(7), 86(52), 74(5), \underline{70(29)}, 62(2)$.

6: $189(59), 173(6), 152(4), 146(39), 131(2), 122(2), 116(23)$, $105(3), 99(21), 92(7), 86(35), 74(2), 70(47), 62(3)$.

7: $203(17), 189(8), 187(114), 177(2), 130(2), 117(13)$, 100 (54), $9 \overline{4(6), 84}(25), 75(4), 64(2)$.

8: $203(43), 189(4), 187(47), 166(4), 160(32), 133(18)$, $122(19), 1 \overline{18(27)}, 105(2), 100(74), 94(7), 84(12), 83(23)$, $75(6), 64(3)$.

a Rel. int. (\% total ion current) given in parentheses. Underlined signals were not used for normalization. A signal indicates a broad signal over several mass numbers.

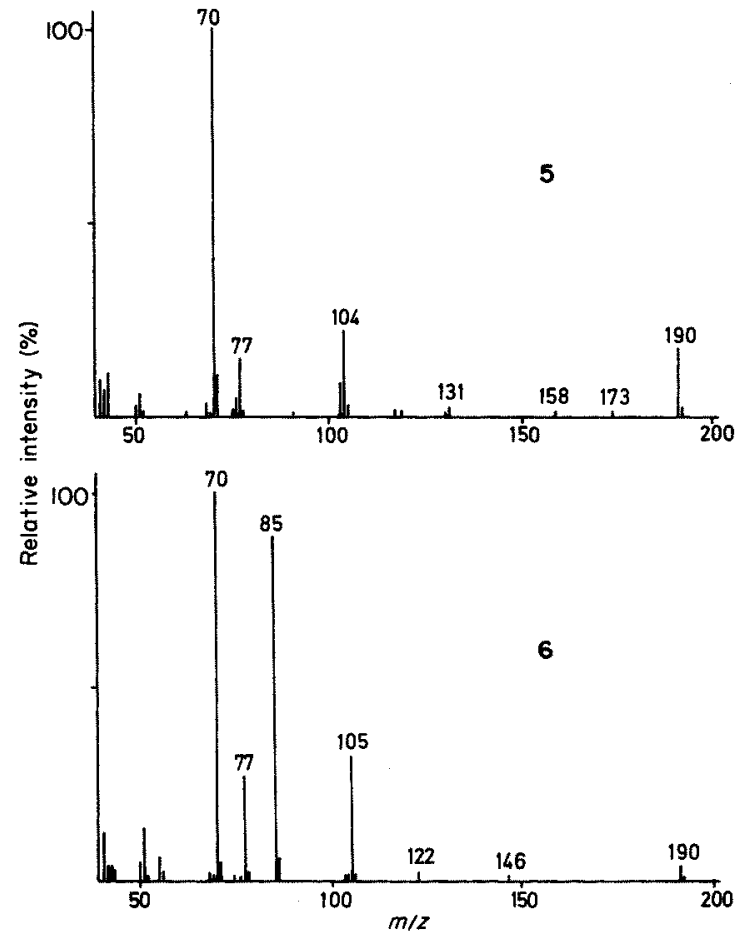

Figure 1. The $70 \mathrm{eV}$ mass spectra of 5 and 6.

ported in the literature. ${ }^{2}$ The intensities of ions $\mathrm{m} / \mathrm{z}$ $105\left({ }^{12} \mathrm{C}_{7} \mathrm{H}_{5} \mathrm{O}\right.$ and $\left.{ }^{13} \mathrm{C}^{12} \mathrm{C}_{6} \mathrm{H}_{6} \mathrm{~N} \approx 1: 5\right)$ and $\mathrm{m} / z 77$ are much less, and those of the molecular ions $\mathrm{m} / \mathrm{z}$ 190 and fragment ions $\mathrm{m} / z \quad 104\left(\mathrm{C}_{7} \mathrm{H}_{6} \mathrm{~N}\right)$ and 70 $\left(\mathrm{C}_{4} \mathrm{H}_{8} \mathrm{~N}\right)$ are much enhanced. Indeed, the main fragmentations of 5 resemble those of 7 and in both cases can be explained by the ketoxime structure of the reacting ions; i.e. loss of $\mathrm{OH}$, formation of $\mathrm{C}_{6} \mathrm{H}_{5} \equiv$ $\stackrel{+}{N H}$ ions, $m / z 104$, and formation of $\left[\mathrm{C}_{4} \mathrm{H}_{8} \mathrm{~N}\right]^{+}$and $\left[\mathrm{C}_{5} \mathrm{H}_{10} \mathrm{~N}\right]^{+}$ions, respectively, from the pyrrolidine and piperidine moiety of 5 and 7 . The only indication of a possible Beckmann rearrangement of $[5]^{+\cdot}$ ions is the small amount of benzoyl ions $\mathrm{m} / z 105$ in the $70 \mathrm{eV}$ mass spectrum of $\mathbf{5}$, but in view of the bad reproducibility of this spectrum between different laboratories it appears that $\mathbf{5}$ is especially sensitive to thermal (catalytic ?) degradation in the inlet system and the ion source of a mass spectrometer.

Furthermore, the $70 \mathrm{eV}$ mass spectra of the amides 6 and $\mathbf{8}$ are very different from those of the isomeric ketoximes. In addition to peaks of the expected fragment ions $m / z 122,105,77$ and $70(6)$ or $84(8)$, large peaks for ions $m / z 85\left(6, \mathrm{C}_{4} \mathrm{H}_{9} \mathrm{~N}_{2}\right)$ and $99(8$, $\mathrm{C}_{5} \mathrm{H}_{11} \mathrm{~N}_{2}$ ) are observed exclusively in the spectra of the amides.

The differences between the fragmentations of the isomers 5 and 6 or 7 and 8 are maintained for the reactions of metastable ions (Tables 2 and 3 ). The loss of a $\mathrm{CH}_{2} \mathrm{NO}$ fragment (probably $\mathrm{OH}+\mathrm{HCN}$ ) is typical for the fragmentation of metastable amide ions $[6]^{+}$ and $[8]^{+\cdot}$. This is observed neither in the MIKE spectra nor in the CA MIKE spectra of the isomers $[5]^{+\cdot}$ and $[7]^{+*}$. Therefore, it is very unlikely that a Beckmann rearrangement is of any importance for the reactions of unstable, metastable and stable molecular ions of the aryl heteryl ketoximes $\mathbf{5}$ and $\mathbf{7}$. However, 
fragmentations by rearrangement reactions of the molecular ions of the heteryl benzamides 6 and 8 and of the heteryl ketoximes 5 and 7 do occur. This is clearly seen from the loss of $\mathrm{OH}$ and $\mathrm{CH}_{2} \mathrm{NO}$ from metastable $[6]^{+\cdot}$ and $[8]^{+\cdot}$ ions and the formation of ions $\left[\mathrm{C}_{4} \mathrm{H}_{8} \mathrm{NO}\right]^{+}, m / z 86$ and $\left[\mathrm{C}_{5} \mathrm{H}_{10} \mathrm{NO}\right]^{+}, \mathrm{m} / z 100$, respectively. The latter ions, which require a transfer of the oxygen atom to the heterocyclic moiety, also give large signals in the CA MIKE spectra of the molecular ions of 5-8. The mechanisms of these novel rearrangements are not yet known and will be investigated further. Probably the formation of a stable aminium ion by hydrogen migration from the heterocyclic ring to the carbonyl group $(6,8)$ or the

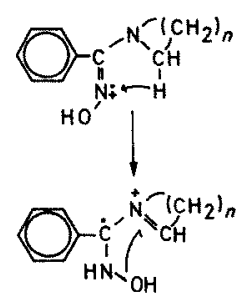<smiles>[13CH3][13CH3]</smiles>

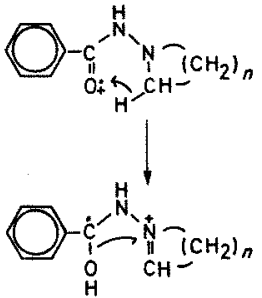

6

Scheme 1 oxime group $(5,7)$ occurs $^{3 a}$ and leads to a reactive form of the molecular ions.

\section{REFERENCES}

1. A. Maquestiau, Y. van Haverbeke, R. Flammang and P. Heyraut, Org. Mass Spectrom. 15, 80 (1980).

2. R. K. M. R. Kallury and P. L. K. M. Rao, Org. Mass Spectrom. 12. 411 (1977).

3. D. Goldsmith, D. Becker, J. Sample and C. Djerassi, Tetrahedron Suppl. 7, 145 (1966); (b) V. Kramer, M. Medved, B. Kralj and J. Marsel, Org. Mass Spectrom. 9, 854 (1974); (c)
D. Hemalatha and R. K. M. R. Kallury, Org. Mass Spectrom. 11, 347 (1975); (d) R. K. M. R. Kallury, A. G. Loudon and A. Maccoll, Org. Mass Spectrom. 13, 218 (1978).

Received 5 February 1982; accepted 5 February 1982.

(C) Heyden \& Son Ltd, 1982 